\title{
Parents' perceptions of obesity prevention during infancy: a qualitative study
}

\author{
Ilona Hale MD, Shazhan Amed MD, Shelly Keidar MSc, Megan Purcell MA, Donna Lee MD, \\ Daniel Farhadi BSc
}

Abstract

Background: Infancy appears to be a critical period for establishing a person's weight set point. It remains unclear which interventions during infancy may be most effective in preventing later obesity and which ones are most acceptable to parents. The aim of this study was to examine the attitudes of parents of children aged 2 years and under toward different obesity prevention messages and their preferences with regard to these messages.

Methods: Using a qualitative research design, we conducted semistructured interviews followed by a focus group. Parents of children under 2 years of age were purposively recruited from 2 communities in British Columbia, Canada, and asked for their opinions about various health promotion messages relating to obesity prevention. A theoretical thematic analysis was used to analyze the data.

Results: Thirty-three parents participated in the study. Participants reported that many of the current recommendations (no screen time, no sugary beverages) are unrealistic, unclear and inconsistent, making them difficult to follow and causing parents to feel guilty; they had a more positive response to the feeding roles message. Parents noted the importance of starting education early and targeting the broader community.

Interpretation: Several important and interesting themes were identified in this study, which increases our understanding of parents' attitudes toward and preferences for the messages presented. Obesity prevention information for today's busy parents needs to be realistic, supportive and timely.

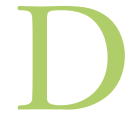
espite decades of research, obesity continues to be a major public health challenge, affecting two-thirds of Canadian adults and one-third of children. Obesity costs between $\$ 4.6$ and $\$ 7.1$ billion annually and contributes to 48000 to 66000 deaths every year in Canada. ${ }^{1}$ Most of the research to date has focused on adults and school-aged children but given that up to $38 \%$ of preschoolers in Canada are already overweight ${ }^{2}$ we may be missing the opportunity for primary prevention. Additionally, many of the factors contributing to obesity appear to have their origins during the critical period of early development in the first year of life when behavioural, neuroendocrine and epigenetic $^{3}$ changes result in programming of a weight set point that is difficult to reverse once established., ${ }^{4,5}$ Only a small number of prospective studies assessing the impact of interventions during infancy have been published to date, most of which have shown some positive effect on parent behaviour or infant weight. ${ }^{6,7}$ Most obesity research has targeted traditional risk factors related to sedentary behaviour and overconsumption of high-calorie, low-nutrient foods. Current recommendations for infants include avoiding all screen time for children under 2 years of age and avoiding sugary beverages including juice. Parental feeding style is emerging as another important modifiable factor. A recent review of early obesity prevention studies concluded: "Interventions that aim to improve parental feeding practices, including infant diet and parental responsiveness to infant cues, showed most promise." ${ }^{8}$ Responsive feeding refers to a feeding style "characterized by appropriate responses to infant cues for hunger, satiety and non-nutritive needs." ${ }^{\prime}$ The division of responsibility or feeding roles approach helps parents implement responsive feeding by delineating parents' and children's "roles" in the feeding relationship: parents decide when, where and what to provide and children decide how much or whether to eat. ${ }^{10}$ Despite its long history, the feeding roles message has not been evaluated directly in a prospective study for obesity

\section{Competing interests: None declared.}

This article has been peer reviewed.

Correspondence to: Ilona Hale, ilona.hale@alumni.ubc.ca

CMAJ Open 2019. DOI:10.9778/cmajo.20180066 
prevention. More research is required to identify which type of educational intervention during infancy may be the most effective in altering parent behaviour and preventing future obesity.

Understanding the perspectives of parents is critical to the success of any behaviour change intervention for families. Although other research has explored parental perceptions of traditional diet and activity recommendations in childhood, ${ }^{11}$ very little has been done to understand parental responses to either (a) the feeding roles message or (b) obesity prevention education during infancy. The newborn and infant periods present multiple unique opportunities for obesity prevention. The current study addresses the following question: In a population of parents of children aged 2 years and under, what are the attitudes toward and preferences for different obesity prevention messages? The objectives are to explore parental attitudes toward messages about screen time, sugary beverages and feeding roles and to better understand parents' preferences for how and when to receive these messages.

\section{Methods}

\section{Setting}

The research was carried out in 2 communities in the Interior Health region of British Columbia, Canada.

\section{Study sample}

We recruited a purposive sample of parents of young children ( 2 years of age and under) using local knowledge of different settings where parents caring for very young children could be found, including a daycare, a support group for young or vulnerable parents and several other programs catering to different types of parents to ensure maximum variation in sampling of parents. We wanted our sample to include parents of different ages and from different socioeconomic groups to reflect the composition of the communities. The research assistant contacted the leaders (early child-care workers) of 6 different groups and requested their assistance with recruitment. Group leaders informed their members of the study, collected the names of interested parents and then forwarded these names to the research assistant. The total number of potential participants who were informed of the study was approximately 100 (group attendance at many of these dropin programs varied and leaders were unable to provide exact numbers). Typically, approximately $10 \%$ of the parents participating in the groups are fathers; this is consistent with the national percentage of primary caregivers who are men. ${ }^{12} \mathrm{We}$ set a target number of participants of between 30 and 40 on the basis of the sample sizes used in similar qualitative research studies. ${ }^{13}$ During the final round of interviews, we determined that no new themes or important ideas were being raised and that more interviews would probably not improve the reproducibility of the study so recruitment was stopped. Three of the participants were personal patients of the principal investigator (I.H.). Of these, only 1was interviewed by the principal investigator.

\section{Design}

We used a qualitative research design guided by 2 relevant behaviour change theories (theory of planned behaviour and social cognitive theory ${ }^{14}$ ) for data collection and analysis. According to these theories, the factors most likely to be associated with behaviour change are a person's knowledge of and attitudes toward the recommendation, social context, level of perceived control over changing the behaviour and the perceived relevance of the message. We (I.H., S.K., M.P.) developed a semistructured interview guide (Appendix 1, available at www.cmajopen.ca/content/7/1/E81/suppl/DC1) using questions related to the key constructs of each theory to explore 3 obesity prevention messages: no screen time, no sugary beverages and feeding roles. We pilot tested and refined the interview guide with several practice interviews. We also collected a variety of health promotion resources to use as tangible examples during the interviews (Appendices $2-4$, available at www.cmajopen.ca/content/7/1/E81/ suppl/DC1).

\section{Data collection}

We conducted semistructured individual interviews in local community centres between Jan. 30 and Mar. 7, 2017. We used the interview guide and the sample resources to explore participants' perspectives about and preferences for different messages, media, presentation and timing. The interviews were conducted by the principal investigator (I.H. [a local physician]) and a research assistant. Both are health professionals with training and experience in patient interviews. The research assistant scheduled interviews at times convenient for the participants and each interview lasted 30-45 minutes. Throughout the interview period, the 2 interviewers conferred regularly to share field notes and experiences. The principal investigator listened to the audiotapes of several of the interviews conducted by the other interviewer to ensure consistency in approach. Interviews were audiorecorded and transcribed by members of the team (I.H., D.L., D.F.) and transcriptionists. Audiofiles and transcripts were shared and stored using a secure share site (share.bcchr.ca).

Following preliminary analysis of the data we shared a summary of the preliminary results (themes) and some modified patient resources with a small focus group of some of the original participants to verify that their views had been adequately represented and to allow for further input.

\section{Analysis}

After reviewing the first 3 interviews to identify important themes, we (I.H., M.P., S.K.) each independently developed an initial coding framework using the principles of theoretical thematic analysis ${ }^{15}$ then we combined these by consensus discussion into 1 framework (Appendix 5, available at www.cmajopen. ca/content/7/1/E81/suppl/DC1). We (I.H., D.L., D.F.) manually coded and analyzed the remaining interviews with minor modifications to the codebook to reflect new themes as they were identified. Every effort was made to ensure the validity and reliability of the results by involving multiple members of the research team in both the initial and ongoing data analysis 
and by iteratively checking the new data against the existing framework to identify and evaluate new ideas and make modifications to the framework as required. ${ }^{16}$

\section{Ethics approval}

The study received ethical approval through a harmonized review from the University of British Columbia Research Ethics Board and the BC Interior Health Research Ethics Board (reference no. 2016-17-058-H).

\section{Results}

We interviewed 33 parents. The participants had a broad range of ages and socioeconomic backgrounds but were mostly women (94\%). More details of the participants' demographics are presented in Table 1. A selection of representative quotations from the parent participants is presented in Table 2.

\section{Attitudes toward traditional obesity prevention messages}

\section{Unrealistic recommendations}

Parents repeatedly emphasized that health promotion messages need to be realistic, taking today's societal norms into consideration. Most parents talked about the many challenges they face raising their children. They reported that health promotion messages that make parenting even more difficult, such as avoiding screen time and sugary drinks, are less likely to be adopted. Most parents recognized the benefits to their children of avoiding excessive screen time, but many felt that zero screen time was probably not realistic for most families as screens are frequently used as a convenient distraction. Trying to keep screens away from young children would require significant changes to parents' own habits and necessitate avoiding restaurants, other peoples' homes and many other settings. Screens and sweetened beverages were also described as very attractive to children. This caused parents to feel conflicted about refusing to allow them since parents intuitively wanted to make their children happy. Many parents made references to guilt and being judged, both for following the recommendations (and denying their children a pleasurable experience that other children may be enjoying) and for failing to follow the recommendations (and being judged to be a "bad" parent).

Single or working parents, wintertime, long car trips and the presence of an older sibling were factors that made avoiding screens and sweet drinks even more difficult. Many parents felt that the zero tolerance guidelines were too black and white and that recommendations for moderation would be more reasonable.

\section{Unclear and inconsistent messaging}

Parents said that it is important that messages be clear and consistent. Parents reported receiving an overwhelming amount of sometimes conflicting information from a variety of sources.
Although many parents felt that black-and-white messages of "no screen time" and "no sweet drinks" were too harsh, others liked the simplicity of these messages. Some parents wanted more explanation of the "why" behind the recommendations to help convince them of their importance and validity.

There was considerable confusion and disagreement about the recommendation to avoid all screen time and $100 \%$ fruit juice. Some parents expressed fear that their infants would be missing out on the potential benefits of technology and the "nutrition" from juice. Increasing the confusion was marketing of both screens ("educational programs") and sweetened beverages ("sports" and "electrolyte replacement" drinks or healthy-sounding " $100 \%$ natural" fruit juices) targeting children. Many parents had been advised by their health care providers to offer juice when their child was ill.

\begin{tabular}{|lc|}
\hline \multicolumn{2}{|l|}{ Table 1: Participant demographics $(\boldsymbol{n}=\mathbf{3 3})$} \\
\hline Characteristic & No. $(\%)^{*}$ \\
\hline Female & $31(94)$ \\
\hline Age, yr & \\
\hline $17-23$ & $5(16)$ \\
\hline $24-30$ & $6(19)$ \\
\hline $31-36$ & $13(42)$ \\
\hline $37-43$ & $7(23)$ \\
\hline Mean & 32 \\
\hline Marital status & \\
\hline Married & $21(64)$ \\
\hline Common law & $8(24)$ \\
\hline Single & $3(9)$ \\
\hline Unknown & $1(3)$ \\
\hline Education level & \\
\hline Some high school & $3(9)$ \\
\hline Completed high school & $6(18)$ \\
\hline College & $10(30)$ \\
\hline University & $13(39)$ \\
\hline Unknown & $1(3)$ \\
\hline Annual household income, \$ & \\
\hline$<30$ 000 & $10(30)$ \\
\hline $31000-60$ 000 & $3(9)$ \\
\hline $61000-90$ 000 & $10(30)$ \\
\hline$>90000$ & $8(24)$ \\
\hline No answer & $2(6)$ \\
\hline Body mass index & $17(52)$ \\
\hline$<25$ & $9(27)$ \\
\hline$>25$ & $7(21)$ \\
\hline Don't know/declined & $18(54)$ \\
\hline Other siblings & \\
\hline *Unless otherwise indicated. & \\
\hline & \\
\hline & \\
\hline & \\
\hline
\end{tabular}


Table 2 (part 1 of 2): Representative quotations from parents

Theme

Quotation

Traditional messages: Parenting is really hard and I don't want to be told off for sitting my kid down in front of a screen, when I need a unrealistic break ... if the consequences are worse ... I don't want to be getting really angry, if I need some time to cool down recommendations then I rather them have the screen time than me lose it. (P12)

I think that it is a great theory but try to work 3 night shifts in a row and not put her in front of the TV for half an hour when I just need her to calm down, or I just need to get something done or go switch the laundry or something. (P10)

I think it [rigid guidelines] is another thing that would make parents feel guilty and another challenge that makes it difficult for parents. (P11)

I think parenting is pretty tough and you get lots of advice and sometimes trying to do it all it, doesn't make you feel so good. (P12)

I have got to be sane for her to be sane and if it means letting her watch a show for 15 minutes then that's fine. (P10)

I think that you need to set realistic goals for parents. (P9)

Traditional messages: $\quad$ There is so much information that you get hit with, you kind of remember bits of it ... you don't remember it [all] unclear and inconsistent messaging correctly. (P12)

I think I have heard no screen time under 2 and then I've heard limit screen time to half an hour a day for maybe over 2 but I am getting them mixed up. So, I am not exactly sure. (P12)

There's like 12 grams of sugar in milk so ... where do you draw the line? (P27)

Sugary drinks and juice is all the same now? It just seems kind of unclear — I thought $100 \%$ juice was recommended in the Food Guide? (P13)

Technology is such an important part of our society these days, that you do not want to completely eliminate it from your child's life. (P3)

Advertising or smart marketing make you think it's healthy; there's a lot of misconceptions around food. (P26)

Novel feeding roles I think it's wonderful - I should put it on my fridge; you can't make your kid eat. (P1)

message

It makes it really black and white ... it's not something you think about, but to see somebody spell it out for you ... you realize that it's important. (P24)

Babies and kids thrive on structure and routine and being able to predict what's going to happen. (P3)

I feel that it is important to be there as a family; you can't force them to eat. (P20)

It's really helped us have a much more pleasant mealtime; before it would get really tense and people would be really unhappy; it makes the whole evening go better. (P4)

Including her in our meal times ... and making it more about a social interaction, suddenly she [is] also like, "Oh yeah, I want to eat too." (P13)

It tells you that your child, if he's not eating then that's totally fine. (P4)

Preferences:

importance of starting

early

I think just knowing this stuff before you kind of start out, before the baby comes is very important. (P10)

I wish I had never given him any form of juice whatsoever because then we wouldn't have had this ongoing battle. (P26)

It is hard after we already set the precedent that you can say you are hungry and you get a snack. It is harder to go back. (P33)

When they're sort of under [age] one, it's pretty easy to control it, but will be tough in daycare.... [now] it's my chance though. (P2)

If they don't know that juice is an option then I don't think they miss it. (P11)

If you start right away, I can't imagine that it would be a problem. (P28)

If it's an infant then it is really easy to say, no you can't have it, but if they are older they can argue with you. (P12)

If they've been following this recommendation, they're not all of a sudden going to start feeding them sugary

drinks because they've built up a healthy habit. (P6) 
Table 2 (part 2 of 2): Representative quotations from parents

\begin{tabular}{|ll|}
\hline $\begin{array}{l}\text { Theme } \\
\text { Preferences: } \\
\text { presentation }\end{array}$ & People don't like reading ... I feel like paper stuff might not ... be the way to go anymore. (P2) \\
\hline & When we went to the hospital, they gave us like this whole package of stuff and it was like "blehh." (P11) \\
\hline & $\begin{array}{l}\text { I prefer it on paper ... I get so overwhelmed with emails, my inbox is full every day ... you just delete it ... I think it } \\
\text { sticks in your mind better, too. (P24) }\end{array}$ \\
\hline & We primarily get our information online ... on Facebook we've created these mom groups. (P16) \\
\hline & I think it's the conversation ... that had the most impact on me, that's what I remember. (P9) \\
\hline $\begin{array}{l}\text { Preferences: } \\
\text { community-based }\end{array}$ & I think if everyone is doing it, it becomes normal. (P12) \\
\hline & There are other programs adopting that no-juice philosophy already. It's easy if it's everywhere, on the same page. (P5) \\
\hline & We go to Strong Start on the Wednesdays and that's great because it is a night off for me and it is a healthy meal. (P12) \\
\hline & I can't really say to my daughter "you can't drink it" [at a party] when everyone [else] is. (P15) \\
\hline The daycare ... they have a really good schedule for the kids so that really helps. (P4) \\
\hline Note: P = participant.
\end{tabular}

\section{Attitudes toward feeding roles message}

In contrast with parental responses to traditional messages that encourage the prohibition of unhealthy habits or behaviours, the parents' response to the more flexible feeding roles message was more positive. Parents intuitively agreed with the concepts and reported that they felt it would help them "choose their battles" and relieve guilt, worry and fighting about whether their child was eating enough. Parents who had tried to follow this recommendation said it was more convenient and pleasant to follow regular schedules, to not have to cook separate meals for their children and to eat together as a family. Some parents expressed concern about their ability to adhere to regularly scheduled meal and snack times.

\section{Preferences}

\section{Timing: the importance of starting early}

Many parents preferred getting obesity prevention information very early and noted that it is much easier to consistently follow healthy guidelines if routines for both parents and children are established from the start. Parents emphasized how comparatively easy it was to control their children's exposure to screens and unhealthy food and drinks during the first year when infants were less mobile and spent more time at home with the primary caregiver. Once children become more independent it is much harder to control their choices. Many parents felt that starting from infancy also increased the chances that children would maintain these healthy habits later.

\section{Presentation}

There was considerable heterogeneity in the responses about preferred media for receiving the messages. Some parents were strongly in favour of print resources while others were strongly opposed to these and preferred digital (web, text or email) information. Most participants preferred simple messages with little text and with attractive, colourful graphics, with more detailed information available for those who are interested. Almost all agreed that face-to-face education was effective and they preferred to get their information from trustworthy sources, specifically health professionals.

\section{Community-based messaging}

Participants consistently emphasized the important influence of their community and the people around them on their choices and reported that when others in the community are aware of the recommendations it makes it easier to make healthy choices. Frequently cited were the schools and daycares that prohibit juice and promote other healthy behaviours. Social events where unhealthy celebration foods were freely offered presented a great challenge for parents. Consistent community-based education campaigns designed to establish new accepted norms made it easier for parents to follow the guidelines. The recently implemented Live 5-2-1-0 initiative (promoting and supporting the daily consumption of 5 servings of fruits and vegetables, under 2 hours of screen time per day, 1 hour of physical activity per day and no sugarsweetened beverages) in 1 of the communities was frequently mentioned as a facilitator of healthy choices. The availability of convenient parent/baby programs that gave parents something to do with their children made it easier to avoid relying on screen time for entertainment, especially in the winter. Spousal support was reported as critical to success in following recommendations.

The follow-up focus group was composed of 3 of the original participants, who confirmed that the major themes identified were consistent with what they had intended to convey. ${ }^{16}$ No important new information was gained from the focus group discussion and no changes were made to the findings. 


\section{Interpretation}

There were several important and interesting themes identified in this study that increase our understanding of parents' attitudes toward and preferences for the messages presented as well as other influences affecting the likelihood that they will follow the various recommendations.

The findings are largely consistent with existing behaviour change theories and studies of parents of older children. ${ }^{11}$ Parents' behaviours and confidence in following recommendations were dependent on their knowledge, attitudes, social context and level of perceived control and the relevance of the messages. Several new findings were identified that appear to be specific to infancy and to the current generation of parents.

Parents repeatedly referred to the challenges of parenting and the importance of finding ways to make their busy lives easier, acknowledging the importance of convenience in decision-making. Many of the tools parents use today to entertain or distract their children and promote "good behaviour" rely on the convenience of screens or sweets. As discussed by $\mathrm{Wu}$, for many people in our fast-paced society, the value of convenience is becoming the primary consideration, trumping all other values. ${ }^{17}$ Many parents indicated that they did not feel able to relinquish something that makes their lives easier, even when they acknowledged the potential negative health implications. For example, most parents admitted that they still often used screens to entertain their children despite feeling guilty about it. Convenience appears to be even more important to many parents than financial cost, which has traditionally been assumed to be an important factor influencing behaviour. This need for convenience may be driven by what Dr. Paul Kershaw describes as "Generation Squeeze": parents are working for less pay than previous generations and have more debt, while also raising young children, caring for aging parents, facing unprecedented challenges of affordability and receiving little support from government social programs despite being the lowest earning segment of the population. ${ }^{18}$

It remains critical to find ways to provide important health messages while respecting and supporting parents' need for convenience. Offering positive suggestions may be more effective than the often-used traditional zero-tolerance policies. Instead of demanding total abstinence (from screens or sweet drinks), messages should explain why minimizing exposure is particularly important for babies and then adopt a more informative, realistic harm reduction approach, as in the following example: Try to watch with your child whenever possible. Avoid screen time while eating and before bedtime and offer short, slow-paced programs with little stimulation. ${ }^{19}$ The feeding roles message was better received than more traditional messages, perhaps because it achieves a more appropriate balance by providing parents with clear, helpful suggestions that actually make their lives easier. If information is provided to parents during their children's infancy it is easier for families to develop healthy habits, because this is the stage at which parents have the most control. Parents should be reassured that enforcing some of these behaviours even for a very short time during this important window may have significant long-term benefits for their child. The perinatal period may also be an optimal time for health workers to provide education because of the established routine of frequent visits combined with the uniquely teachable moment ${ }^{20}$ during which parents are highly motivated to make decisions to protect and nurture their babies.

Participants in our study recognized that simple things such as a daycare or school introducing a "no juice" policy were very helpful in raising awareness, establishing community norms and supporting parents' efforts at home. Successful obesity prevention education should include promotion to the broader community to help create an environment where parents are supported in their social context in making healthy choices, so that the entire burden of responsibility does not fall on individual families.

\section{Limitations}

The participants in this study, although socioeconomically diverse, were culturally homogeneous (reflecting the study communities, which are mostly of European descent). Fathers represented only $6 \%$ of the sample, which could be perceived as a limitation; however, this reflects the typical proportion of fathers who are the primary caregivers for their children $(5 \%-$ $10 \%) .{ }^{12}$ The results from these 2 communities may not be applicable to other groups, especially large urban populations. All of the findings are based on parent self-report. One of the interviewers was a local family physician, which may have introduced some social desirability bias. The 2 interviewers in this study did not have previous experience conducting qualitative research interviews; however, they were provided with guidance and support by more experienced researchers.

\section{Conclusion}

This study provides useful information for designing appropriate obesity prevention interventions during infancy but also has broader implications for health promotion aimed at this important demographic group. The findings have led to the development of a pilot intervention study that will focus on the responsive feeding roles message during infancy.

\section{References}

1. Ogilvie KK, Eggleton A. Obesity in Canada a whole-of-society approach for a healthier Canada. Ottawa: Standing Senate Committee on Social Affairs, Science and Technology; 2016:56.

2. Twells LK, Newhook LA. Obesity prevalence estimates in a Canadian regional population of preschool children using variant growth references. BMC Pediatr 2011;11:21

3. Desai MM, Jellyman JK, Ross MG. Epigenomics, gestational programming and risk of metabolic syndrome. Int 7 Obesity (Lond) 2015;39:633-41.

4. Anderson JW, Konz EC, Frederich RC, et al. Long-term weight-loss maintenance: a meta-analysis of US studies. Am 7 Clin Nutr 2001;74:579-84.

5. Dattilo AM. Modifiable risk factors and interventions for childhood obesity prevention within the first 1000 days. Nestle Nutr Inst Workshop Ser 2017;87: 183-96.

6. Laws R, Campbell KJ, van der Pligt P, et al. The impact of interventions to prevent obesity or improve obesity related behaviours in children ( $0-5$ years $)$ from socioeconomically disadvantaged and/or indigenous families: a systematic review. BMC Public Health 2014;14:779.

7. Dattilo AM, Birch L, Krebs NF, et al. Need for early interventions in the prevention of pediatric overweight: a review and upcoming directions. 7 Obes 2012;2012:123023.

8. Redsell SA, Edmonds B, Swift JA, et al. Systematic review of randomised controlled trials of interventions that aim to reduce the risk, either directly or indirectly, of overweight and obesity in infancy and early childhood. Matern Child Nutr 2016;12:24-38. 
9. Harbron J, Booley S, Najaar B, et al. Responsive feeding: establishing healthy eating behaviour early on in life. South Afr 7 Clin Nutr 2013;26:141-9.

10. Eneli IU, Tylka TL, Hummel J, et al. Rationale and design of the Feeding Dynamic Intervention (FDI) study for self-regulation of energy intake in preschoolers. Contemp Clin Trials 2015;41:325-34.

11. Pocock M, Trivedi D, Wills $W$, et al. Parental perceptions regarding healthy behaviours for preventing overweight and obesity in young children: a systematic review of qualitative studies. Obes Rev 2010;11:338-53.

12. Changing profile of stay-at-home parents. Ottawa: Statistics Canada; 2018. Available: https://www150.statcan.gc.ca/n1/pub/11-630-x/11-630-x2016007-eng. htm (accessed 2018 Nov. 16).

13. Dworkin SL. Sample size policy for qualitative studies using in-depth interviews. Arch Sex Behav 2012;41:1319-20.

14. Motivating behavior change. Brussels (Belgium): European Food Information Council. 2014.

15. Braun V, Clark V. Using thematic analysis in psychology. Qual Res Psychol 2006;3:77-101.

16. Morse JM, Barrett M, Mayan M, et al. Verification strategies for establishing reliability and validity in qualitative research. Int 7 Qual Methods 2002;1:13-22.

17. Wu T. The tyranny of convenience. The New York Times. 2018 Feb. 16.

18. Kershaw P, Anderson L. Is a pan-Canadian early child development system possible? Yes, when we redress what ails Canadian culture. Paediatr Child Health 2009; $14: 685-8$.

19. Screen time and young children: promoting health and development in a digital world. Paediatr Child Health 2017;22:461-8.

20. Phelan S. Pregnancy: a "teachable moment" for weight control and obesity prevention. Am 7 Obstet Gynecol 2010;202:135.e1-8.
Affiliations: Department of Family Practice (Hale) and School of Population and Public Health (Lee), University of British Columbia; British Columbia Children's Hospital and SCOPE BC (Sustainable Childhood Obesity Prevention through Community Engagement) (Amed, Keidar), Vancouver, BC; East Kootenay Division of Family Practice (Purcell), Cranbrook, BC; College of Medicine (Farhadi), University of Saskatchewan, Saskatoon, Sask.

Contributors: Ilona Hale was involved in all aspects of the study. Shazhan Amed was involved in the conception and design of the study and the interpretation of the data. Shelly Keidar and Megan Purcell were involved in the conception of the study and the analysis and interpretation of the data.. Donna Lee and Daniel Farhadi contributed substantially to the analysis and interpretation of the data. Ilona Hale drafted the article. All authors revised the article critically for important intellectual content, gave final approval of the version to be published and agree to act as guarantors of the work.

Acknowledgements: The authors are grateful for the support of Dee Taylor of the Interior Health Research Department, and to Dr. Wendy Norman and Dr. Stefan Gryzbowski of the UBC Department of Family Practice for their invaluable assistance with this research.

Supplemental information: For reviewer comments and the original submission of this manuscript, please see www.cmajopen.ca/content/7/1/ E81/suppl/DC1. 